\title{
Magnetic and Electrical Properties of Gd Doped $\mathrm{Ni}-\mathrm{Cu}-\mathrm{Zn}-\mathrm{Fe}_{2} \mathrm{O}_{4}$
}

\author{
P. Venkata Srinivasa Rao ${ }^{1,2 *}$, T. Anjaneyulu ${ }^{3}$, D. V. Krishna Reddy ${ }^{1}$, M. Rami Reddy ${ }^{1}$ \\ ${ }^{1}$ Department of Physics, Acharya Nagarjuna University, Guntur, India \\ ${ }^{2}$ Department of Physics, S. S. \& N. College, Guntur, India \\ ${ }^{3}$ Department of Physics, Narasaraopeta Engineering College, Guntur, India \\ Email: *pvsrinivasphd@gmail.com
}

How to cite this paper: Srinivasa Rao, P.V., Anjaneyulu, T., Krishna Reddy, D.V. and Rami Reddy, M. (2018) Magnetic and Electrical Properties of Gd Doped Ni-Cu$\mathrm{Zn}-\mathrm{Fe}_{2} \mathrm{O}_{4}$. Advances in Materials Physics and Chemistry, 8, 401-410.

https://doi.org/10.4236/ampc.2018.810027

Received: September 17, 2018

Accepted: October 14, 2018

Published: October 18, 2018

Copyright (C) 2018 by authors and Scientific Research Publishing Inc. This work is licensed under the Creative Commons Attribution International License (CC BY 4.0).

http://creativecommons.org/licenses/by/4.0/

\begin{abstract}
$\mathrm{Ni}_{0.5} \mathrm{Cu}_{0.25} \mathrm{Zn}_{0.25} \mathrm{Gd}_{\mathrm{x}} \mathrm{Fe}_{2-\mathrm{x}} \mathrm{O}_{4}(\mathrm{x}=0.0,0.025,0.05,0.075,0.1)$ ferrites were synthesized using an oxalic-based precursor method. The $\mathrm{T}_{\mathrm{C}}$ for all the $\mathrm{Ni}_{0.5} \mathrm{Cu}_{0.25} \mathrm{Zn}_{0.25} \mathrm{Gd}_{\mathrm{x}} \mathrm{Fe}_{2-\mathrm{x}} \mathrm{O}_{4}(\mathrm{x}=0.0,0.025,0.05,0.075,0.1)$ samples was measured by using one of the double coil susceptibility setup. In all the samples it is observed that, at a certain temperature, susceptibility falls to zero indicating the Curie temperature $\left(\mathrm{T}_{\mathrm{C}}\right)$ and ferrimagnetic samples are converted into paramagnetic sample at that temperature. The electrical properties were investigated for these samples. Dielectric properties and $\rho_{\mathrm{dc}}$ properties were observed to decrease with the increase in the frequency for all the Gd doped ferrite samples.
\end{abstract}

\section{Keywords}

Ni-Cu-Zn-Gd Nanoferrites, Magnetic Properties, Electrical Properties

\section{Introduction}

Spinel Ni-Cu-Zn ferrites are one of the potential materials used in high frequency applications and in magnetic storage devices [1]. They are used as recording heads, inductors, deflection yokes, transformer cores, etc. [2] [3]. These ferrites with different chemical compositions in different forms like, thin films and nano powder have been investigated for their structural, electrical and magnetic properties in recent years. In these ferrites, if partial doping of $+2,+3$ ions are replaced in the place of $\mathrm{Fe}^{3+}$ ions, it may lead to the structural distortion thereby enhancing the magnetic properties. Rare earth doped $\mathrm{Ni}-\mathrm{Cu}-\mathrm{Zn}$ ferrites results in the improved magnetic and optical properties [4] [5] [6] [7] [8]. Higher percentage of rare earth doping in ferrites usually contributes for the formation 
of rare earth secondary phases, and is observed for only few kind of rare earth elements [9]. It is well known that the magnetic properties of the ferrite materials depends on the type, ionic radius and concentration of the doping ions (magnetic/nomagnetic nature) [10], grain and morphology of the samples and methods of preparation [11] [12]. Doping these ferrites with various transition elements leads to important changes in their structural, electrical and magnetic properties.

Synthesis of $\mathrm{Gd}$ doped $\mathrm{Ni}-\mathrm{Cu}-\mathrm{Zn}$ ferrites is a challenging task because of co-existence of undesired phase like $\mathrm{Fe}_{2} \mathrm{O}_{3}$ along with the spinel. It is known that rare-earth ions play an important role in determining the magnetocrystalline anisotropy in 4f-3d intermetallic compounds [13]. The presence of $\mathrm{Gd}^{3+}$ ions influences mainly the magnetic anisotropy of the system. The magnetic properties of ferrites can be changed by the substitution of various kinds of divalent ions or by introducing a relatively small amount of rare-earth ions. Substitution of rare earth ion into the spinel structure has been reported to lead to structural distortion and to induce strains and to significantly modify the electrical and magnetic properties [14] [15]. It is found that all the rare earth ions favor in the occurrence of secondary phases resulting in the increase of bulk density and electrical resistivity [16] [17]. From our literature review we observed that till now no researcher have reported Gd doped $\mathrm{Ni}_{0.5} \mathrm{Cu}_{0.25} \mathrm{Zn}_{0.25} \mathrm{Fe}_{2} \mathrm{O}_{4}$ ferrite. Therefore, in this present work, we made an attempt for systematic doping of $\mathrm{Gd}$ in Ni-Cu-Zn ferrite synthesized using oxalic acid-based precursor method [18] [19] [20] to investigate their magnetic and electrical properties.

\section{Experimental Procedure}

$\mathrm{Ni}_{0.5} \mathrm{Cu}_{0.25} \mathrm{Zn}_{0.25} \mathrm{Gd}_{\mathrm{x}} \mathrm{Fe}_{2-\mathrm{x}} \mathrm{O}_{4}(\mathrm{x}=0.0,0.025,0.05,0.075,0.1)$ ferrite nanopowders were synthesized using an oxalate-based precursor method [18] [19] [20]. All the chemicals used were a.r. grade from Sigma-Aldrich and had purities $\geq 99 \%$. In this synthesis process, nickel nitrate hydrate $\left(\mathrm{Ni}\left(\mathrm{NO}_{3}\right)_{2} \cdot 6 \mathrm{H}_{2} \mathrm{O}\right)$, cupric nitrate hydrate $\left(\mathrm{Cu}\left(\mathrm{NO}_{3}\right)_{2} \cdot 6 \mathrm{H}_{2} \mathrm{O}\right)$, zinc nitrate hydrate $\left(\mathrm{Zn}\left(\mathrm{NO}_{3}\right)_{2} \cdot 6 \mathrm{H}_{2} \mathrm{O}\right)$, gadolinium oxide $\left(\mathrm{Gd}_{2} \mathrm{O}_{3}\right)$ and ferric nitrate nonahydrate $\left(\mathrm{Fe}\left(\mathrm{NO}_{3}\right)_{3} \cdot 9 \mathrm{H}_{2} \mathrm{O}\right)$ were used as the starting materials. The entire synthesis process is described elsewhere [19]. The resultant mixtures were evaporated on a hot plate at $\sim 150^{\circ} \mathrm{C}$ for $2 \mathrm{~h}$. The obtained raw powders were thermally heat treated at $450^{\circ} \mathrm{C}$ for $4 \mathrm{~h}$. The $\mathrm{T}_{\mathrm{C}}$ for all the $\mathrm{Ni}_{0.5} \mathrm{Cu}_{0.25} \mathrm{Zn}_{0.25} \mathrm{Gd}_{\mathrm{x}} \mathrm{Fe}_{2-\mathrm{x}} \mathrm{O}_{4}(\mathrm{x}=0.0,0.025,0.05,0.075,0.1)$ samples was measured by using one of the double coil susceptibility setup. The dielectric properties were measured using a Nova Control, Alpha high performance frequency analyzer.

\section{Results and Discussions}

The Curie temperature $\left(\mathrm{T}_{\mathrm{C}}\right)$ for all the samples was measured by using one of the double coil susceptibility models available. The graphs of the magnetization vs absolute temperature $\mathrm{T}$ are plotted which are shown in Figure 1. The plots of all 
the samples show ferrimagnetic behavior. In all the cases it is found that at a certain temperature, susceptibility falls to zero indicating the Curie temperature $\left(T_{C}\right)$ and ferrimagnetic sample is converted into paramagnetic sample.

In the present system $\mathrm{Ni}_{0.5} \mathrm{Cu}_{0.25} \mathrm{Zn}_{0.25} \mathrm{Gd}_{\mathrm{x}} \mathrm{Fe}_{2-\mathrm{x}} \mathrm{O}_{4}(\mathrm{x}=0.0,0.025,0.05,0.075$, 0.1 ) we have obtained the Curie temperature as $426^{\circ} \mathrm{C}$ for

$\mathrm{Ni}_{0.5} \mathrm{Cu}_{0.25} \mathrm{Zn}_{0.25} \mathrm{Gd}_{\mathrm{x}} \mathrm{Fe}_{2} \mathrm{O}_{4}$ samples. From this observation we can say that due to non-magnetic Gd doping $T_{C}$ is decreased. Curie temperatures $T_{C}$ of all the samples are given in Table 1 and the variation of $\mathrm{T}_{\mathrm{C}}$ with $\mathrm{x}$ is shown in Figure 2. From Figure 2, it is observed that $T_{C}$ keeps on decreasing due to increasing non-magnetic $\mathrm{Gd}^{3+}$ content $x$. This indicates that ferrimagnetic behavior reduces with addition of non-magnetic $\mathrm{Gd}^{3+}$ ions. This is accredited to decrease in magnetic (A-B) interactions and increase in (B-B) interaction due to the substitution of $\mathrm{Fe}$ ions $\mathrm{Gd}$ ions. The substitution of $\mathrm{Gd}^{3+}$ ions reduces the active magnetic moment therefore the $\mathrm{T}_{\mathrm{C}}$ goes on decreasing with increase in non-magnetic $\mathrm{Gd}$ content $x$ in this ferrite system. The results of A. C. susceptibility are in good agreement with those of magnetization.

Table 1. Curie temperature $\left(\mathrm{T}_{\mathrm{C}}\right)$ of $\mathrm{Ni}_{0.5} \mathrm{Cu}_{0.25} \mathrm{Zn}_{0.25} \mathrm{Gd}_{\mathrm{x}} \mathrm{Fe}_{2-\mathrm{x}} \mathrm{O}_{4}(\mathrm{x}=0.0,0.025,0.05,0.075$, $0.1)$ ferrites.

\begin{tabular}{cc}
\hline $\mathbf{x}$ & $\mathrm{Tc}\left({ }^{\circ} \mathrm{C}\right)$ \\
\hline 0 & 426 \\
0.025 & 385 \\
0.05 & 319 \\
0.075 & 252 \\
0.1 & 213 \\
\hline
\end{tabular}

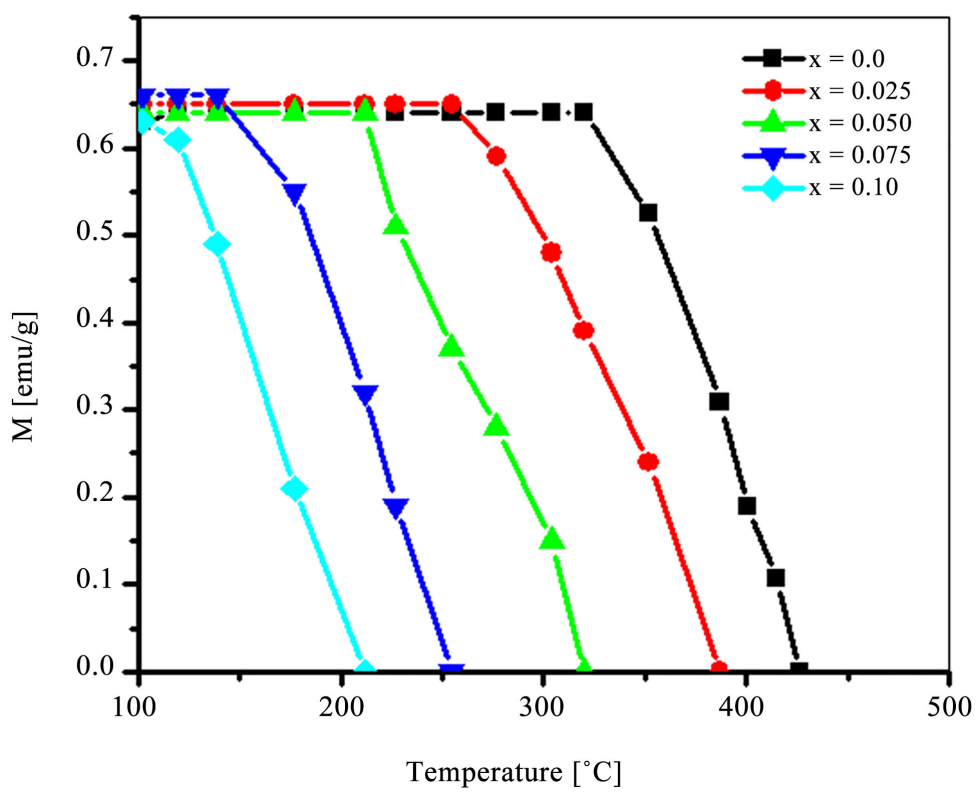

Figure 1. Curie temperature $\left(T_{C}\right)$ measurements for $\mathrm{Ni}_{0.5} \mathrm{Cu}_{0.25} \mathrm{Zn}_{0.25} \mathrm{Gd}_{\mathrm{x}} \mathrm{Fe}_{2-\mathrm{x}} \mathrm{O}_{4}$ $(\mathrm{x}=0.0,0.025,0.05,0.075,0.1)$ ferrites samples. 


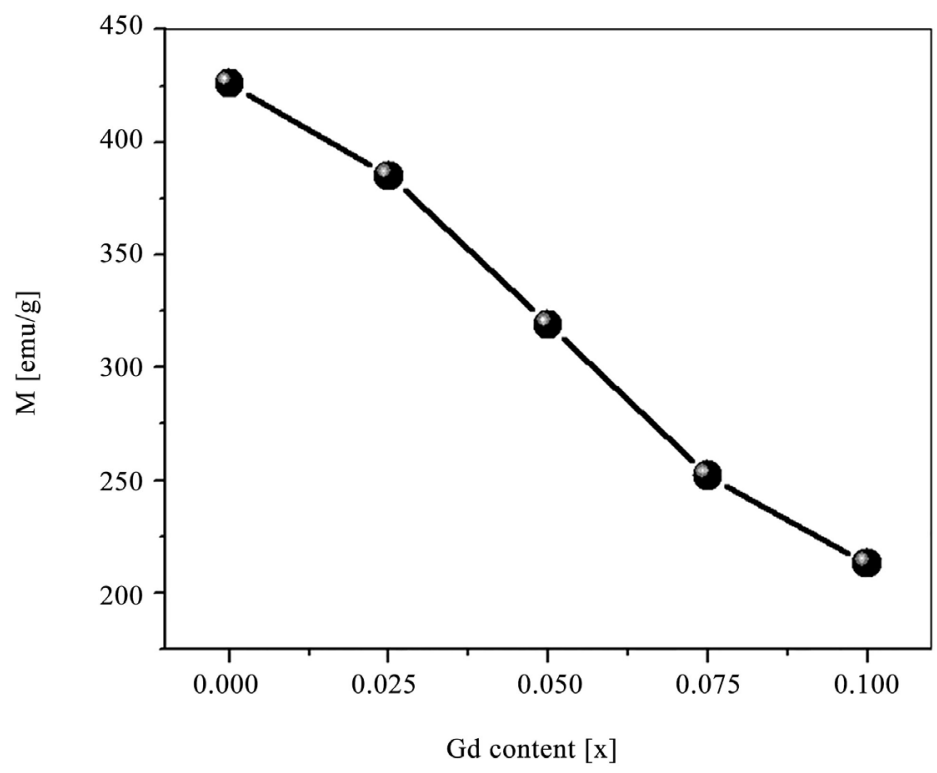

Figure 2. Curie temperature $\left(T_{C}\right)$ with Gd content $x$ for $\mathrm{Ni}_{0.5} \mathrm{Cu}_{0.25} \mathrm{Zn}_{0.25} \mathrm{Gd}_{\mathrm{x}} \mathrm{Fe}_{2-\mathrm{x}} \mathrm{O}_{4}$ $(\mathrm{x}=0.0,0.025,0.05,0.075,0.1)$ ferrites samples.

The dielectric behavior among ferrites is considered to be one of the most important electrical properties that predominantly based on the synthesis technique, annealing time, annealing temperature and type of dopant and its quantity. The variations in the dielectric constant $\left(\varepsilon^{\prime}\right)$ with frequency for $\mathrm{Ni}_{0.5} \mathrm{Cu}_{0.25} \mathrm{Zn}_{0.25} \mathrm{Gd}_{\mathrm{x}} \mathrm{Fe}_{2-\mathrm{x}} \mathrm{O}_{4}(\mathrm{x}=0.0,0.025,0.05,0.075,0.1)$ ferrites samples are shown in Figure 3. All the samples are observed to exhibit dielectric dispersion. The dielectric constant was observed to decrease initially with increasing frequency and then to become almost constant at higher frequencies. Different grain sizes show different dielectric constants but the behaviors are same. At a certain frequency, these samples show a frequency-independent characteristic behavior that can be explained using the well-known Maxwell-Wagner-type interfacial polarization, that is in accord with Koop's theory [21] [22] [23]. The dielectric polarization among ferrites is same as that of the conduction mechanism taking place with hopping of electronics. Hopping of electrons among the $\mathrm{Fe}^{3+}$ $\mathrm{Fe}^{2+}$ in the applied field direction takes place to determine the polarization. With the increase in frequency the polarization decreases and attains a constant value. This is based on the fact, that after a particular applied frequency, the electron will exchange between $\mathrm{Fe}^{2+} \leftrightarrow \mathrm{Fe}^{3+}$ which may not follow the alternating electric field. Higher dielectric constant values at lower frequencies will be due to greater number of $\mathrm{Fe}^{2+}$ ions, interfacial dislocations, grain boundary defects, oxygen vacancies [21] [22] [23] [24]. The decrease in the dielectric constant ( $\left.\varepsilon^{\prime}\right)$ with increasing frequency is a natural phenomenon due to the fact that any element contributing to polarization will show a lagging effect with the applied field at larger frequencies.

The observed dielectric constant values for our NiCuZnGd ferrite samples are little more than those reported for NiCuZn ferrite synthesized by using different 
processes and different compositions. The conduction mechanism among the ferrites is majorly due to the hopping of electrons of the same element with different oxidation states. The lower dielectric constant values are observed among ferrites that are annealed at lower temperatures due to the low chance of ions existing with different valance states which reduces the probability of hopping electrons [24] [25] [26] [27] [28]. Also, the grain/particle size, density, stoichiometry and homogeneity of the ferrites are observed to affect the dielectric constant values [26]. Therefore, as our samples are annealed at higher temperatures, the dielectric constants are observed to be more.

The $\tan \delta$ with the applied frequency is measured at room temperature. The dielectric loss tangent data plotted in Figure 4 clearly shows that in all the samples the dielectric loss tangent slowly increased with the increase of frequency till a particular frequency, after which it slowly decreases. Different grain sizes show different dielectric loss tangent curves and different values. With the application of an external alternating field having the same frequency, the maximum electrical energy will be transfer to the oscillating ions; due to this, the power loss in the ferrites rises [24] [27]. The peaks in the dielectric loss tangent appear with the applied field time is in phase with the dielectric and when the condition, $\omega \tau$ $=1$ is satisfied, where $\omega=2 \pi \mathrm{f}$, $\mathrm{f}$ is the applied field frequency, $\tau$ is the relaxation time, which is connected to the jumping probability unit time $p$ using the equation $\tau=p / 2$; i.e., the peak frequency $\left(\mathrm{f}_{\max }\right)$ is relative to the jumping probability. With the increase in $f_{\max }$ and in the annealing temperature, the jumping or hopping probability increases.

Figure 5 shows, the temperature dependent dc resistivity, represented as (log $\left.\rho_{\mathrm{dc}}\right)$ vs $(1000 / \mathrm{T})$, for all the synthesized samples. It is clearly seen that $\rho_{\mathrm{dc}}$ in all

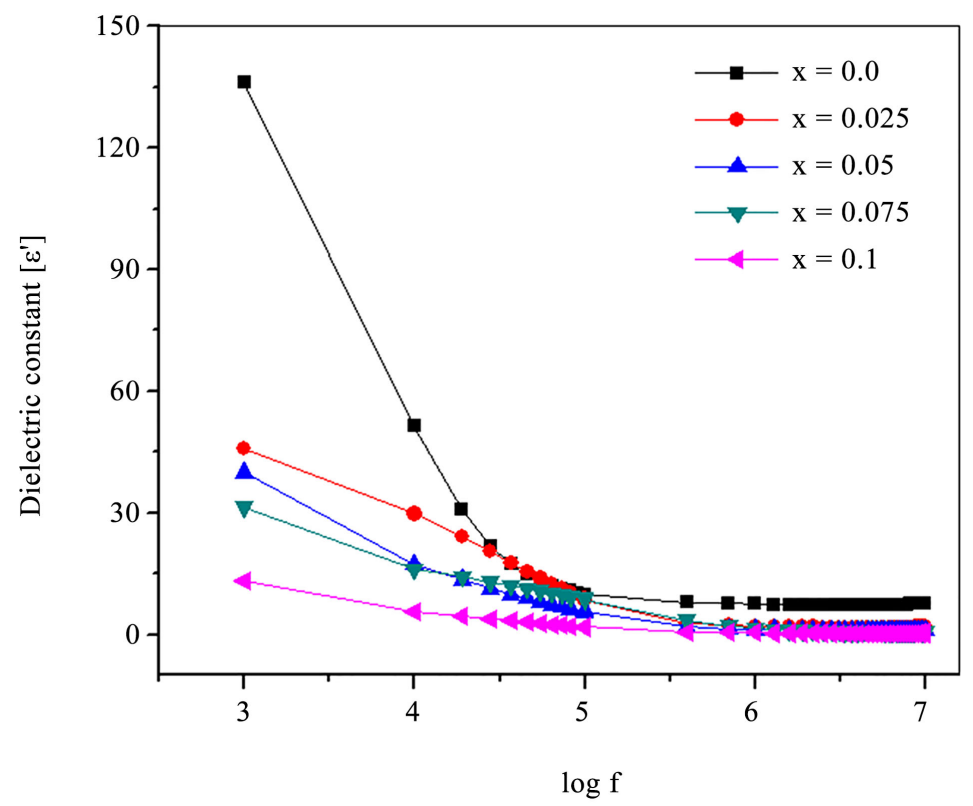

Figure 3. Variations of the dielectric constant for $\mathrm{Ni}_{0.5} \mathrm{Cu}_{0.25} \mathrm{Zn}_{0.25} \mathrm{Gd}_{\mathrm{x}} \mathrm{Fe}_{2-\mathrm{x}} \mathrm{O}_{4}(\mathrm{x}=0.0$, $0.025,0.05,0.075,0.1)$ ferrites. 


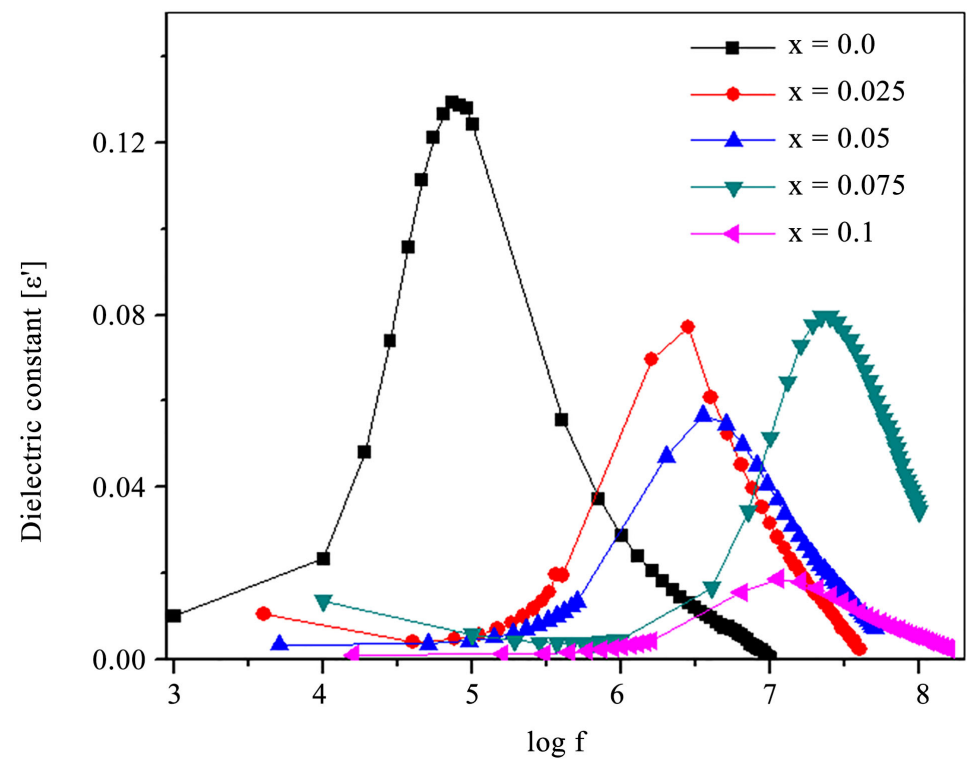

Figure 4. Variations of the dielectric loss tangent for $\mathrm{Ni}_{0.5} \mathrm{Cu}_{0.25} \mathrm{Zn}_{0.25} \mathrm{Gd}_{\mathrm{x}} \mathrm{Fe}_{2-\mathrm{x}} \mathrm{O}_{4}(\mathrm{x}=0.0$, $0.025,0.05,0.075,0.1)$ ferrites.

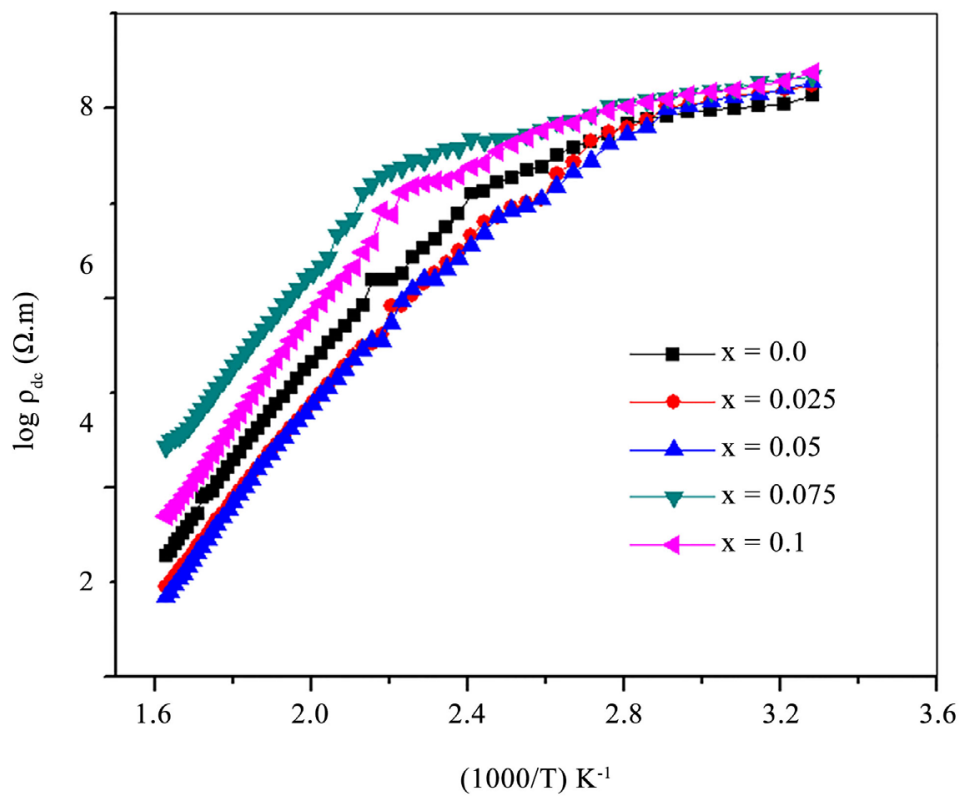

Figure 5. The variation of $\log (\rho)$ with $1000 / \mathrm{T}$ for $\mathrm{Ni}_{0.5} \mathrm{Cu}_{0.25} \mathrm{Zn}_{0.25} \mathrm{Gd}_{\mathrm{x}} \mathrm{Fe}_{2-\mathrm{x}} \mathrm{O}_{4}(\mathrm{x}=0.0$, $0.025,0.05,0.075,0.1)$ ferrites.

the samples decreased with the increase in temperature. This kind of results are somewhat common feature among ferrites signifying the normal semiconducting nature explained by Arrheneus relation (1) [29].

$$
\rho=\rho_{0} \exp \left(\frac{E}{K_{B} T}\right)
$$

where $\rho_{0}$ is the resistivity at infinitely high temperature, $K$ is the Boltzmann constant, $T$ is the absolute temperature and $\Delta E$ is activation energy. 
Further, from Figure 5 that, each of these curves can be differentiated into the two regions having different activation energies. Contrary, the transition temperatures, $\mathrm{T} \rho$, in between the first region and the second region was observed to be near to the values measured from magnetic measurements [30]. The transition taking place at $\mathrm{T} \rho$ is the activation energy at which the magnetic transition is taking place from ferrimagnetic state to the paramagnetic (region one to region second) state. The activation energies in ferrimagnetic and paramagnetic regions were designated as EF and EP. The activation energies values were determined from the least square method as the function of $\mathrm{Gd}^{3+}$ ions [31]. The impact of these magnetic transitions of ferrites on the electrical applications was reported in literature by several researchers [32] [33]. It is evident that the EP values are higher than the $\mathrm{EF}$ in all the samples accordance with [34]. As a matter of fact, all most all the ferrites exhibit a change at the activation energy around $\mathrm{T}_{\mathrm{C}}$ so that $\mathrm{EP}>\mathrm{EF}$ [32]. The increase in the activation energy near the paramagnetic region compared to the ferrimagnetic region can be accredited to the development of spin polarons [35] [36]. It is observed that the condition for the formation of spin polaron is, the activation energy in $\mathrm{EP}>0.2 \mathrm{eV}$, as in similar to our samples [35] [37]. Therefore our entire sample favors spin polarons formation [38] [39] [40].

\section{Conclusion}

The $\mathrm{Ni}_{0.5} \mathrm{Cu}_{0.25} \mathrm{Zn}_{0.25} \mathrm{Gd}_{\mathrm{x}} \mathrm{Fe}_{2-\mathrm{x}} \mathrm{O}_{4}(\mathrm{x}=0.0,0.025,0.05,0.075,0.1)$ ferrite samples were successfully prepared using the oxalic method. XRD results showed single phase spinel ferrite structure. The Curie temperature $\left(\mathrm{T}_{\mathrm{C}}\right)$ was observed to decrease with increasing Gd concentration. The dielectric properties and $\rho_{\mathrm{dc}}$ were observed to decrease with the increase in the frequency for all the Gd doped ferrite samples.

\section{Conflicts of Interest}

The authors declare no conflicts of interest regarding the publication of this paper.

\section{References}

[1] Mukesh Dimri, C., Subhash Kashyap, C. and Dube, D.C. (2010) High Frequency Behaviour of Low Temperature Sintered Polycrystalline NiCuZn Ferrites and Their Composite Thick Films. Physica Status Solidi A, 207, 396. https://doi.org/10.1002/pssa.200824475

[2] Nakamura, T. (1997) Low-Temperature Sintering of NiZnCu Ferrite and Its Permeability Spectra. Journal of Magnetism and Magnetic Materials, 168, 285. https://doi.org/10.1016/S0304-8853(96)00709-3

[3] Harzali, H., Saida, F., Marzouki, A., Megriche, A., Baillon, F., Espitalier, F. and Mgaidi, A. (2016) Structural and Magnetic Properties of Nano-Sized NiCuZn Ferrites Synthesized by Co-Precipitation Method with Ultrasound Irradiation. Journal of Magnetism and Magnetic Materials, 419, 50. https://doi.org/10.1016/j.jmmm.2016.05.084 
[4] Eltabey, M.M., El-Shokrofy, K.M. and Gharbia, S.A. (2011) Enhancement of the Magnetic Properties of Ni-Cu-Zn Ferrites by the Non-Magnetic $\mathrm{Al}^{3+}$-Ions Substitution. Journal of Alloys and Compounds, 509, 2473. https://doi.org/10.1016/j.jallcom.2010.11.056

[5] Kaiser, M. (2017) Effect of Rare Earth Elements on the Structural, Magnetic and Electrical Behavior of Ni-Zn-Cr Nanoferrites. Journal of Alloys and Compounds, 719, 446. https://doi.org/10.1016/j.jallcom.2017.05.155

[6] Abdellatif, M.H., El-Komy, G.M. and Azab, A.A. (2017) Magnetic Characterization of Rare Earth Doped Spinel Ferrite. Journal of Magnetism and Magnetic Materials, 442, 445. https://doi.org/10.1016/j.jmmm.2017.07.020

[7] Hochschild, R. and Fuess, H. (2000) Rare-Earth Doping of Nickel Zinc Ferrites. Journal of Materials Chemistry, 10, 539. https://doi.org/10.1039/a905583e

[8] Yang, L., Han, D., Liu, H., Liu, Y., Yang, Sh. and Bayanheshig, Z.W. (2015) Effects of Annealing Temperature on the Magnetic Properties of $\mathrm{ZnFe}_{1.97} \mathrm{Eu}_{0.03} \mathrm{O}_{4}$ Nanoparticles. Journal of Materials Science: Materials in Electronics, 26, 6848. https://doi.org/10.1007/s10854-015-3300-0

[9] Roy, P.K. and Bera, J. (2009) Electromagnetic Properties of Samarium-Substituted NiCuZn Ferrite Prepared by Auto-Combustion Method. Journal of Magnetism and Magnetic Materials, 321, 247. https://doi.org/10.1016/j.jmmm.2008.08.051

[10] He, Y., Lei, C., Lin, Q., Dong, J., Yu, Y. and Wang, L. (2015) Mössbauer and Structural Properties of La-Substituted $\mathrm{Ni}_{0.4} \mathrm{Cu}_{0.2} \mathrm{Zn}_{0.4} \mathrm{Fe}_{2} \mathrm{O}_{4}$ Nanocrystalline Ferrite. Science of Advanced Materials, 7, 1809. https://doi.org/10.1166/sam.2015.2394

[11] Suguna, S., Shankar, S., Jaganathan, S.K. and Manikandan, A. (2016) Novel Synthesis of Spinel $\mathrm{Mn}_{\mathrm{x}} \mathrm{Co}_{1-\mathrm{x}} \mathrm{Al}_{2} \mathrm{O}_{4}$ ( $\mathrm{x}=0.0$ to 1.0) Nanocatalysts: Effect of $\mathrm{Mn}^{2+}$ Doping on Structural, Morphological, and Opto-Magnetic Properties. Journal of Superconductivity and Novel Magnetism, 30, 691. https://doi.org/10.1007/s10948-016-3866-7

[12] Padmapriya, G., Manikandan, A., Krishnasamy, V., Jaganathan, S.K. and Antony, S. A. (2016) Enhanced Catalytic Activity and Magnetic Properties of Spinel $\mathrm{Mn}_{\mathrm{x}} \mathrm{Zn}_{1-\mathrm{x}} \mathrm{Fe}_{2} \mathrm{O}_{4}$ Nano-Photocatalysts by Microwave Irradiation Route. Journal of Superconductivity and Novel Magnetism, 29, 2141. https://doi.org/10.1007/s10948-016-3527-x

[13] Zaho, L., Han, Z., Yang, H., Yu, L., Cui, Y., Jin, W. and Feng, S. (2007) Magnetic Properties of Nanocrystalline $\mathrm{Ni}_{0.7} \mathrm{Mn}_{0.3} \mathrm{Gd}_{0.1} \mathrm{Fe}_{1.9} \mathrm{O}_{4}$ Ferrite at Low Temperatures. Journal of Magnetism and Magnetic Materials, 309, 11. https://doi.org/10.1016/j.jmmm.2006.03.054

[14] Kamala Bharathi, K., Arout Chelvana, J. and Markandeyulu, G. (2009) Magnetoelectric Properties of Gd and Nd-Doped Nickel Ferrite. Journal of Magnetism and Magnetic Materials, 321, 3677. https://doi.org/10.1016/j.jmmm.2009.07.011

[15] Kamala Bharathi, K., Balamurugan, K., Santhosh, P.N., Pattabiraman, M. and Markandeyulu, G. (2008) Magnetocapacitance in Dy-Doped Ni Ferrite. Physical Review B, 77, 172401. https://doi.org/10.1103/PhysRevB.77.172401

[16] Hemeda, O.M., Said, M.Z. and Barakat, M.M. (2001) Spectral and Transport Phenomena in Ni Ferrite-Substituted $\mathrm{Gd}_{2} \mathrm{O}_{3}$. Journal of Magnetism and Magnetic Materials, 224, 132-142. https://doi.org/10.1016/S0304-8853(00)00578-3

[17] Alexandre, R.B., Maria, L.G. and Maria, C.S.N. (2007) Effect of Mn Substitution on the Microstructure and Magnetic Properties of $\mathrm{Ni}_{0.50-\mathrm{x}} \mathrm{Zn}_{0.50-\mathrm{x}} \mathrm{Mn}_{2 \mathrm{x}} \mathrm{Fe}_{2} \mathrm{O}_{4}$ Ferrite Prepared by the Citrate-Nitrate Precursor Method. Material Chemistry and Physics, 105, 229-233. https://doi.org/10.1016/j.matchemphys.2007.04.047

[18] Raghavender, A.T., Sagar, E.S. and Vijaya Kumar, K. (2011) Synthesis and Study of 
Nanocrystalline Ni-Cu-Zn Ferrites Prepared by Oxalate Based Precursor Method. Journal of Alloys and Compounds, 509, 7004-7008. https://doi.org/10.1016/j.jallcom.2011.03.127

[19] Wickham, D.G., Mark, J. and Knox, K. (2007) Metal Iron (III) Oxides. Inorganic Synthesis, 9, 152-156. https://doi.org/10.1002/9780470132401.ch41

[20] Chaudhari, N.D., Kambale, R.C., Patil, J.Y., Sawant, S.R. and Suryavanshi, S.S. (2010) Studies on Initial Permeability and Loss Factor in Ni-Zn Ferrites Synthesized by Oxalate Precursors. Materials Research Bulletin, 45, 1713-1719. https://doi.org/10.1016/j.materresbull.2010.06.058

[21] Maxwell, J.C. (1954) A Treatise on Electricity and Magnetism. Oxford, New York, Vol. 2.

[22] Wagner, K.W. (1913) Theory of Dielectric Material. Annaledn Der Physik, 40, 817-855. https://doi.org/10.1002/andp.19133450502

[23] Koops, C.G. (1951) On the Dispersion of Resistivity and Dielectric Constant of Some Semiconductors at Audio frequencies. Physical Review, 83, 121-124. https://doi.org/10.1103/PhysRev.83.121

[24] Raghavender, A.T. and Jadhav, K.M. (2009) Dielectric Properties of Al-Substituted Co Ferrite Nanoparticles. Bulletin of Material Science, 32, 575-578. https://doi.org/10.1007/s12034-009-0087-8

[25] Penchal Reddy, M., Madhuri, W., Balakrishnaiah, G., Ramamanohar Reddy, N., Siva Kumar, K.V., Murthy, V.R.K. and Ramakrishna Reddy, R. (2011) Microwave Sintering of Iron Deficient Ni-Cu-Zn Ferrites for Multilayer Chip Inductors. Current Applied Physics, 11, 191-198. https://doi.org/10.1016/j.cap.2010.07.005

[26] Ahmed, T.T., Rahman, I.Z. and Rahman, M.A. (2004) Study on the Properties of the Copper Substituted NiZn Ferrites. Journal of Materials Processing Technology, 153-154, 797-803. https://doi.org/10.1016/j.jmatprotec.2004.04.188

[27] Ravi Kumar, G., Venudhar, Y.C., Raghavender, A.T. and Vijaya Kumar, K. (2012) Electrical Properties of Copper Substituted Nickel Ferrites. Journal of the Korean Physical Society, 60, 1082-1086. https://doi.org/10.3938/jkps.60.1082

[28] Smit, J. and Wijn, H.P.J. (1959) Ferrites: Physical Properties of Ferromagnetic Oxides in Relation to Their Technical Applications. Clever-Hume Press, London, 233.

[29] Eltabey, M.M., Agami, W.R. and Mohsen, H.T. (2013) Improvement of the Magnetic Properties for Mn-Ni-Zn Ferrites by Rare Earth $\mathrm{Nd}(3+)$ Ion Substitution. Journal of Advanced Research, 5, 601-605. https://doi.org/10.1016/j.jare.2013.08.005

[30] Agami, W.R. (2018) Effect of Neodymium Substitution on the Electric and Dielectric Properties of Mn-Ni-Zn Ferrite. Physica B: Condensed Matter, 534, 17-21. https://doi.org/10.1016/j.physb.2018.01.021

[31] Joshi, G.K., Knot, A.Y. and Sawant, S.R. (1987) Electrical Conductivity Studies of Copper-Substituted and Non-Substituted Ni-Zn Mixed Ferrites. Journal of Material Science, 22, 1694-1700. https://doi.org/10.1007/BF01132394

[32] Sattar, A.A., El-Sayed, H.M. and Agami, W.R. (2008) Study of the Electrical Properties of Calcium-Substituted Li-Zn Ferrite. Physica Status Solidi, 205, 2716-2721. https://doi.org/10.1002/pssa.200824042

[33] Sattar, A.A., El-Sayed, H.M. and El-Tabey, M.M. (2005) The Effect of Al-Substitution on Structure and Electrical Properties of Mn-Ni-Zn Ferrites. Journal of Material Science, 40, 4873-4879. https://doi.org/10.1007/s10853-005-3884-5

[34] Patil, M.G., Mahajan, V.C., Lotke, S.D., Bhise, S.V. and Patil, A. (1994) Electrical 
Resistivity and Thermoelectric Power of Ti Substituted Ni-Cd Ferrites. Solid State Communications, 91, 667-670. https://doi.org/10.1016/0038-1098(94)90568-1

[35] Ravinder, D. and Latha, K. (1999) Dielectric Behaviour of Mixed Mg-Zn Ferrites at Low Frequencies. Materials Letters, 41, 247-253. https://doi.org/10.1016/S0167-577X(99)00138-X

[36] Rezlescu, N., Rezlescu, E., Pasnicu, C. and Craus, M.L. (1994) Effects of the Rare-Earth Ions on Some Properties of a Nickel-Zinc Ferrite. Journal of Physics. Condensed Matter, 6, 5707-5716. https://doi.org/10.1088/0953-8984/6/29/013

[37] Mansour, S.F., Abdo, M.A. and Kzar, F.L. (2018) Effect of Cr Dopant on the Structural, Magnetic and Dielectric Properties of $\mathrm{Cu}-\mathrm{Zn}$ Nanoferrites. Journal of Magnetism and Magnetic Materials, 465, 176-185.

https://doi.org/10.1016/j.jmmm.2018.05.104

[38] Bellad, S.S., Watawe, S.C. and Chougule, B.K. (1999) Some ac Electrical Properties of Li-Mg Ferrites. Materials Research Bulletin, 34, 1099-1106. https://doi.org/10.1016/S0025-5408(99)00107-5

[39] Tilley, R.J.D. (2013) Understanding Solids: The Science of Materials. Wiley, Hoboken, 395.

[40] Bellad, S.S. and Chougule, B.K. (2000) Composition and Frequency Dependent Dielectric Properties of Li-Mg-Ti Ferrites. Materials Chemistry and Physics, 66, 58-63. https://doi.org/10.1016/S0254-0584(00)00273-X 